\title{
Effect of inoculum size, inducer and metal ion on lipase production by Rhodococcus strain UCC 0009
}

\author{
Maegala Nallapan Maniyam ${ }^{1,2 *}$, Anupriya Sundarajoo ${ }^{1}$, Hazeeq Hazwan Azman ${ }^{1,2}$, Nor \\ Suhaila Yaacob ${ }^{1,2}$, and Hasdianty Abdullah ${ }^{1,3}$ \\ ${ }^{1}$ Institute of Bio-IT Selangor, Universiti Selangor, Jalan Zirkon A7/A, Seksyen 7, 40000 Shah Alam, \\ Selangor Darul Ehsan, Malaysia. \\ ${ }^{2}$ Centre for Foundation and General Studies, Universiti Selangor, Jalan Timur Tambahan, 45600 \\ Bestari Jaya, Selangor Darul Ehsan, Malaysia. \\ ${ }^{3}$ Faculty of Engineering and Life Sciences, Universiti Selangor, Jalan Timur Tambahan, 45600 \\ Bestari Jaya, Selangor Darul Ehsan, Malaysia.
}

\begin{abstract}
Lipases are critical enzymes for industrial applications such as in the food and pharmaceutical fields. Therefore, the discovery of new lipases with enhanced characteristics are always encouraged. Thus, the present study explored the ability of a novel bacterial strain isolated from a tropical climate for lipase production. The optimization method using the one-variable-at-a-time approach was adopted to obtain increased production of lipase. The strain identified as Rhodococcus strain UCC 0009 was able to generate specific lipase activity of $11.67^{\mathrm{a}} \pm 0.00 \mathrm{mU} / \mathrm{mg}$ at optimized conditions of $8 \%(\mathrm{v} / \mathrm{v})$ inoculum concentration, $1 \%(\mathrm{v} / \mathrm{v})$ olive oil as the inducer, and the addition of $\mathrm{Ca}^{2+}$ ions. The specific lipase activity increased by $162 \%$ when the optimization using a one-variable-ata-time approach was adopted compared to that of the non-optimized counterpart, signifying this experimental phase's importance. The present study's findings revealed the potential of utilizing Rhodococcus strain UCC 0009 as a green lipase producer for application in bioremediation and biotransformation at an industrial scale. Further study concentrating on enzyme characterization and improving culture conditions for conducive production of lipase via statistical optimization using response surface methodology (RSM) will be attempted to elucidate further the superiority of lipase obtained from local resources.
\end{abstract}

\section{Introduction}

Lipases are versatile enzymes, and as a result, they are the third most abundantly used enzymes after proteases and amylases [1]. This biocatalyst is widely employed in many industries, namely food, pharmaceutical, detergent, leather, textile, cosmetics, and paper [2]. Many sources can secrete lipase ubiquitously, namely plants, animals, insects, and microorganisms [3]. Among these diverse sources, microbial enzymes are the most

\footnotetext{
*Corresponding author: maegala@unisel.edu.my; maegala_81@yahoo.com
} 
appealing due to their valuable attributes such as ease of culture handling, ready accessibility, and high suitability for industrial applications. These lipases can tolerate the hardy industrial environment [4].

Microbial lipases include fungal, yeast, and bacterial lipases. The classification of bacterial lipases, in particular, can be divided into intracellular (glycoproteins) and extracellular (lipoproteins), and they are constitutive [5]. Bacterial lipases are reported to be more often substrate nonspecific and thermostable in addition to being abundant [3]. Bacterial lipases often originate from Streptomyces sp., Alcaligenes sp., Arthrobacter, Pseudomonas sp., Chromobacterium, and Achromobacter sp. [5]. Among all these, bacterial lipases from Staphylococcus sp. and Pseudomonas sp. are commercially employed in high titer [5]. Also, Bacillus performs well as lipase producer due to many exciting features, such as surviving in extreme climatic conditions [6]. Since bacterial lipases demonstrate excellent prospects for lipase production, the need to screen for more bacterial lipases from different genus and isolation sources is in great demand. In line with this, Rhodococcus has been discovered as a potential lipase-producing bacterial strain that can positively establish the library of bacterial lipases applicable in the industry as green biocatalyst [7].

Being actinobacteria, Rhodococcus is continuously researched to discover new enzyme activities since they have a broad spectrum of physiological and metabolic activities and genetics [8]. The genus Rhodococcus has diverse catabolic pathways, which in turn enable them to function efficiently as biocatalyst for degradation and transformation of a wide variety of natural organic and xenobiotic compounds [9]. Rhodococcus can be presented as fitting inocula for bioremediation and bioconversion due to their remarkable ability to metabolize a broad spectrum of the chemical spectrum, the capability to tolerate toxic substrate and solvents, and their persistence to thrive under extreme environmental conditions [10]. Besides, Rhodococcus possess attractive property (catabolite repression), which enabled them to metabolize pollutants such as hydrocarbons, phenols, and nitriles (organic cyanide). However, relatively simpler carbon sources are present in the mixture [10]. Realizing the potential of Rhodococcus as a green biocatalyst, the Institute of Bio-IT Selangor, Universiti Selangor (Unisel) has embarked on the journey to isolate different strains of Rhodococcus from diverse resources in Peninsular Malaysia. To date, the Unisel Culture Collection Unit has an extensive collection of 24 Rhodococcus strains. These strains are competent to degrade many industrial pollutants, namely textile dyes such as methyl orange [11], methyl red [12], and methylene blue [13], phenol [14], and cyanide [15]. Besides, these strains were able to transform nitrile into useful by-products for industrial applications [16].

Even though Rhodococcus has been recognized as a good lipase producer, a preliminary study has been executed, particularly in Rhodococcus originating from the tropical climate for lipase production. Therefore, locally isolated Rhodococcus strain UCC 0009 was attempted as the biological tool to produce lipase, which is useful to transform waste cooking oil (WCO) to biodiesel and glycerol. The present study explored the prospect of enhancing the secretion of lipase through the optimization of inoculum concentration. Furthermore, the effect of different types of inducers and metal ions for improved lipase production from Rhodococcus strain UCC 0009 was investigated. The authors are hopeful that the discovery of the optimum factors for the production of lipase from Rhodococcus strain UCC 0009 from the current research will reveal the essential evidence to design the methodology for mass production of lipase for industrial applications. 


\section{Method}

\subsection{Chemicals}

Sigma (USA), Systerm (Malaysia), Fisher Scientific (Singapore) or Merck (Germany) were the suppliers for chemicals employed in this study, which were used without further purification.

\subsection{Preparation of inoculum (seed culture) of Rhodococcus strain UCC 0009}

Rhodococcus strain UCC 0009 was routinely sustained on nutrient agar plates $(20 \mathrm{~g} / \mathrm{L})$ and incubated at $30{ }^{\circ} \mathrm{C}$ (MEMMERT 108L Incubator INB500, Germany). After 36 hours of the incubation period, a loopful of the strain from the nutrient agar plate was transferred into $100 \mathrm{~mL}$ of nutrient broth $(8 \mathrm{~g} / \mathrm{L})$ and incubated for 24 hours in an incubator shaker (Jeio Tech SI-600R, Korea) at $30{ }^{\circ} \mathrm{C}$ and $160 \mathrm{rpm}$ to prepare the seed culture (inoculum).

\subsection{Production of lipase from Rhodococcus strain UCC 0009}

The formulation of the production medium adhered to the following recipe: minimal salt medium (MSM) of $0.1 \%$ (w/v) $\left(\mathrm{NH}_{4}\right)_{2} \mathrm{SO}_{4}, 0.09 \%$ (w/v) $\mathrm{K}_{2} \mathrm{HPO}_{4}, 0.06 \%$ (w/v) $\mathrm{KH}_{2} \mathrm{PO}_{4}$, $0.02 \%(\mathrm{w} / \mathrm{v}) \mathrm{MgSO}_{4} .7 \mathrm{H} 20,0.01 \%(\mathrm{w} / \mathrm{v})$ yeast extract and $1 \%(\mathrm{v} / \mathrm{v})$ sunflower oil. When the seed culture's optical density at $600 \mathrm{~nm}$ reached 0.6 to 0.8 (denoting the exponential phase of the Rhodococcus strain UCC 0009 growth pattern), $8 \%$ (v/v) of the inoculum was transferred into $50 \mathrm{~mL}$ production medium. The flasks were left to agitate at $160 \mathrm{rpm}$ for 24 hours at $30^{\circ} \mathrm{C}$.

\subsection{Optimization of culture conditions for improved production of lipase from Rhodococcus strain UCC 0009}

The effects of operational conditions were varied to examine Rhodococcus strain UCC 0009 to secrete improved titer of the enzyme lipase. The batch experiments were performed in the production medium using the seed culture of Rhodococcus strain UCC 0009 cultivated in nutrient broth and incubated for 24 hours, as communicated earlier. The optimization study was carried out in triplicates, and the min of results was reported. The control experiment was duplicated without the addition of the inoculum (seed culture). Table 1 summarizes the factors that were optimized in the present study. The rest of the factors, namely temperature, $\mathrm{pH}$, and incubation time, were standardized at $30^{\circ} \mathrm{C}, \mathrm{pH} 7$, and 24 hours.

Table 1. List of factors for improved production of lipase from Rhodococcus strain UCC 0009.

\begin{tabular}{|c|c|c|}
\hline No. & Factor & Range \\
\hline 1. & $\begin{array}{c}\text { Size of } \\
\text { inoculum }(\% \\
\mathrm{v} / \mathrm{v})\end{array}$ & $4,8,12,16$ and 20 \\
\hline 2. & $\begin{array}{c}\text { Types of } \\
\text { inducer }(1 \% \\
(\mathrm{v} / \mathrm{v}))\end{array}$ & $\begin{array}{c}\text { Olive oil, canola oil, coconut oil, corn oil, sunflower oil, sesame oil, } \\
\text { mustard oil, composite 1 (sunflower oil + canola oil) and composite 2 } \\
\text { (palm oil + peanut oil + sesame oil) }\end{array}$ \\
\hline 3. & Metal ions & $\mathrm{K}^{+}, \mathrm{Mg}^{2+}, \mathrm{Ca}^{2+}, \mathrm{Ba}^{2+}$ and $\mathrm{Co}^{2+}$ \\
\hline
\end{tabular}




\subsection{Lipase extraction from $R h$ odococcus strain UCC 0009}

The optimization study was terminated once the incubation period reached 24 hours. The cells were separated from the production medium through centrifugation (Eppendorf 5702R, South Asia) at $4400 \mathrm{rpm}$ for 30 minutes. The supernatant was carefully removed, and the remaining cell pellet was washed twice with $0.05 \mathrm{M}$ potassium phosphate buffer with a $\mathrm{pH}$ value of 7 . The washed cells were then dissolved in fresh $2 \mathrm{~mL}$ of the same buffer. For the study involving the effect of types of inducers on lipase secretion, $3 \mathrm{~mL}$ of $0.1 \%$ Triton X-100 was added to cells, vortexed briefly to unstiffen, and solubilize the aggregated cells, and incubated for 30 minutes at room temperature. Cryogenic grinding was selected as the disruption method to obtain the lipase extract. The cells were placed in a pre-chilled mortar, added with liquid nitrogen, and left for 40 seconds before commencing the grinding process for an uninterrupted period of 10 minutes. The lysed cells were centrifuged at $4400 \mathrm{rpm}$ for 20 minutes to collect the extracted lipase's resulting supernatant.

\subsection{Determination of protein content and lipase activity}

The extracted lipase from cryogenic grinding was evaluated for protein content and lipase activity following previously published methods [7].

\subsection{Statistical analysis}

The Excel application was employed to determine the error bars obtained from triplicate data for each optimization study. SPSS version 20.0 was used as the software to evaluate differences between groups based on a one-way ANOVA test with a $95 \%$ confidence interval ( $\mathrm{p}<0.05$ is regarded as statistically significant). Post-hoc analysis using the Duncan test was applied to determine the most optimum value for each examined factor.

\section{Results and discussion}

There is a massive demand for lipase production, as reflected by the upward trending of their applications in industrial and biotechnological domains. Therefore, the discovery of novel lipases with enhanced attributes is highly pursued. In the present study, the size of the inoculum of Rhodococcus strain UCC 0009 and the effect of inducer (triacylglycerol supplement) was evaluated for the enhanced production of lipase activity.

\subsection{Optimization of inoculum size}

Fig. 1 shows the relationship between the size of the inoculum of the locally isolated Rhodococcus strain UCC 0009 with lipase yield. Specific lipase activity ranging from $2.09^{\mathrm{d}}$ $\mathrm{mU} / \mathrm{mg} \pm 0.06 \mathrm{mU} / \mathrm{mg}$ to $4.45^{\mathrm{a}} \pm 0.01 \mathrm{mU} / \mathrm{mg}$ was obtained from this optimization study. It is clear from Fig. 1 that $8 \%(\mathrm{v} / \mathrm{v})$ size of inoculum resulted in the highest specific lipase activity of $4.45^{\mathrm{a}} \pm 0.01 \mathrm{mU} / \mathrm{mg}$. This might be due to the optimum level of enzyme synthesized from an adequate number of cells obtained at this seed culture concentration [17]. Similar findings were reported using an $8 \%(\mathrm{v} / \mathrm{v})$ seed culture of Rhizopus oryzae for optimum production of lipase after four days of incubation period [18]. In contrast, Malaysian Rhizopus sp. was found to use an inoculum concentration of $2 \%(\mathrm{v} / \mathrm{v})$ for the 
highest lipase activity of $58.63 \mathrm{U} /$ gram dry solids [19]. This indicated that different microorganism requires a different optimum condition to stimulate the production of lipase.

Increasing the inoculum concentration beyond $8 \%(\mathrm{v} / \mathrm{v})$ harmed the production of lipase (Figure 1). This may be attributed to the fact that the substrates were utilized for growth and impeded lipase synthesis [17]. Also, the inhibitory effect on lipase production was observed at higher seed culture concentration due to a lack of oxygen [20]. The experimental procedure at $4 \%(\mathrm{v} / \mathrm{v})$ resulted in $2.32^{\mathrm{c}} \pm 0.10 \mathrm{mU} / \mathrm{mg}$ of specific lipase activity, recording $48 \%$ lower specific lipase activity compared to that of the optimum condition at $8 \%(\mathrm{v} / \mathrm{v})$. The bacterial biomass could not propagate sufficiently at a lower concentration of seed culture, therefore disrupting metabolites' production due to slow substrate conversion [18].

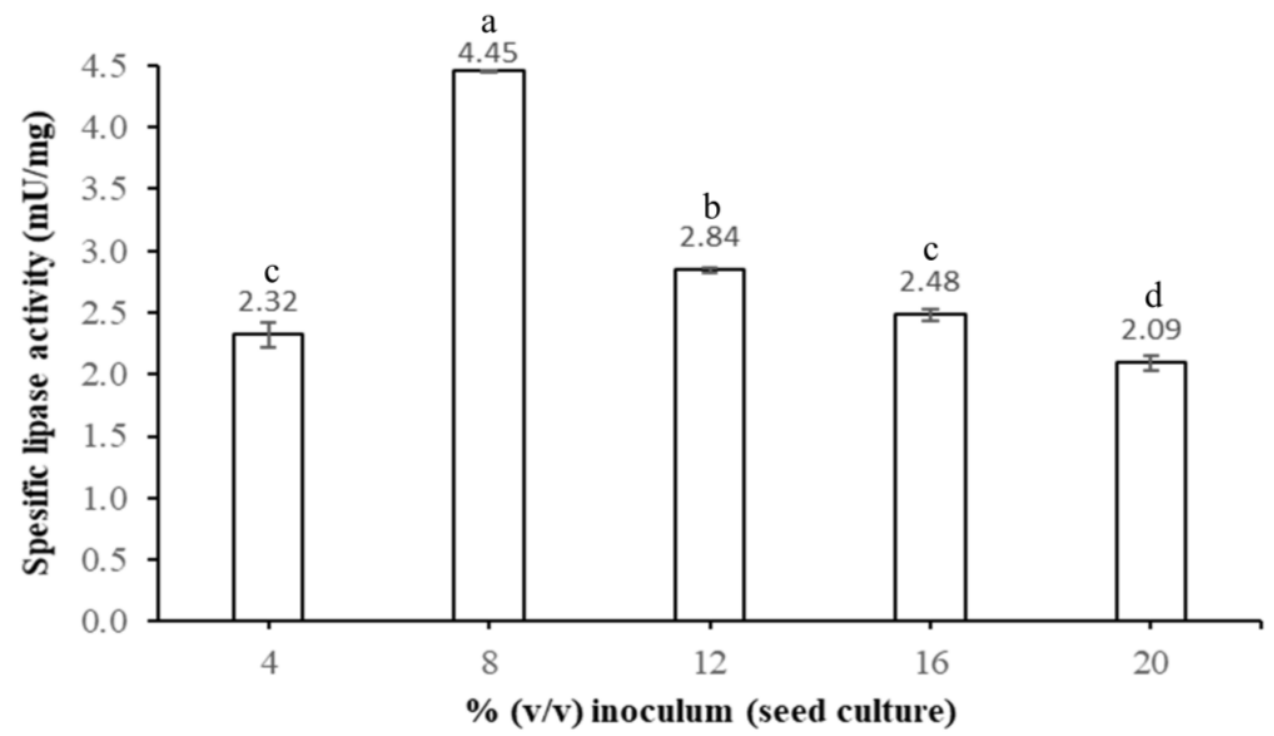

Fig. 1. Effect of inoculum concentration on the production of lipase by Rhodococcus strain UCC 0009. No seed culture was added to the control system. The value of specific lipase activity was determined as averages of triplicate samples \pm standard errors. Statistically significant differences ( $p$ $<0.05$ ) were observed among the tested group. Different letters were used to rank the most optimum factors to the least optimum ( most optimum $={ }^{\mathrm{a}}$; least optimum $={ }^{\mathrm{d}}$ ).

\subsection{Optimization of types of inducer}

The synthesis of lipase is mostly controlled by the presence of carbon chain moiety of the fatty acid commonly found in the triacylglycerol [21]. Natural oils, namely olive oil, canola oil, coconut oil, corn oil, sunflower oil, sesame oil, and mustard oil, are often utilized as inducers for the secretion of the enzyme lipase. A high lipase yield can also be acquired from lipidic carbon sources comprising of fats and vegetable oils, which are regarded as principal sources of lipidic carbon [22].

It was interesting to note that the utilization of sesame oil and coconut oil did not induce the production of lipase in the locally isolated Rhodococcus strain UCC 0009, and therefore no lipase activity was detected in the production medium. Moreover, the addition of corn oil as the inducer did not support the secretion of lipase substantially, recording a specific lipase activity of $1.39^{c} \pm 0.00 \mathrm{mU} / \mathrm{mg}$. No significant difference $(\mathrm{p}<0.05)$ in terms of specific lipase activity was observed when canola oil, sunflower oil, mustard oil, composite 
one and composite two was employed as the inducers, respectively yielding similar specific lipase activity between the range of $1.63^{\mathrm{b}} \pm 0.00 \mathrm{mU} / \mathrm{mg}$ to $1.99^{\mathrm{b}} \pm 0.00 \mathrm{mU} / \mathrm{mg}$.

As illustrated in Fig. 2, it was relatively straightforward that lipase's highest specific activity was observed when olive oil was used as the inducer and sole carbon source in this case, resulting in $8.89^{\mathrm{a}} \pm 0.05 \mathrm{mU} / \mathrm{mg}$. Each oil has different lipid composition, which might account for the difference in the specific lipase activity when utilized as the inducer [23]. Two factors positively influence lipase production as an inducible enzyme, namely the type and concentration of lipid sources in the fermentation media, such as fatty acids [23]. Olive oil emerged as the best inducer for lipase production in Rhodococcus strain UCC 009 since it contains high oleic acid content, which most lipases are specific towards, and low linoleic acid content, which have been reported to have a detrimental impact on lipase productivity [22]. A couple of studies supported the present research finding, which indicated olive oil as the most optimum inducer to aid the secretion of lipase from the local isolate. Improved lipase production from Aspergillus niger was observed when $5 \%(\mathrm{v} / \mathrm{v})$ and $1 \%(\mathrm{v} / \mathrm{v})$ olive oil were used as the inducer [22,23], which coincided with the outcomes from the present study. However, a study established coconut oil as the inducer and sole carbon source in promoting the highest lipase activity from Aspergillus tamarii. Nevertheless, natural vegetable oil utilization seems to be the best inducer to support the secretion of lipase from microorganisms [24].

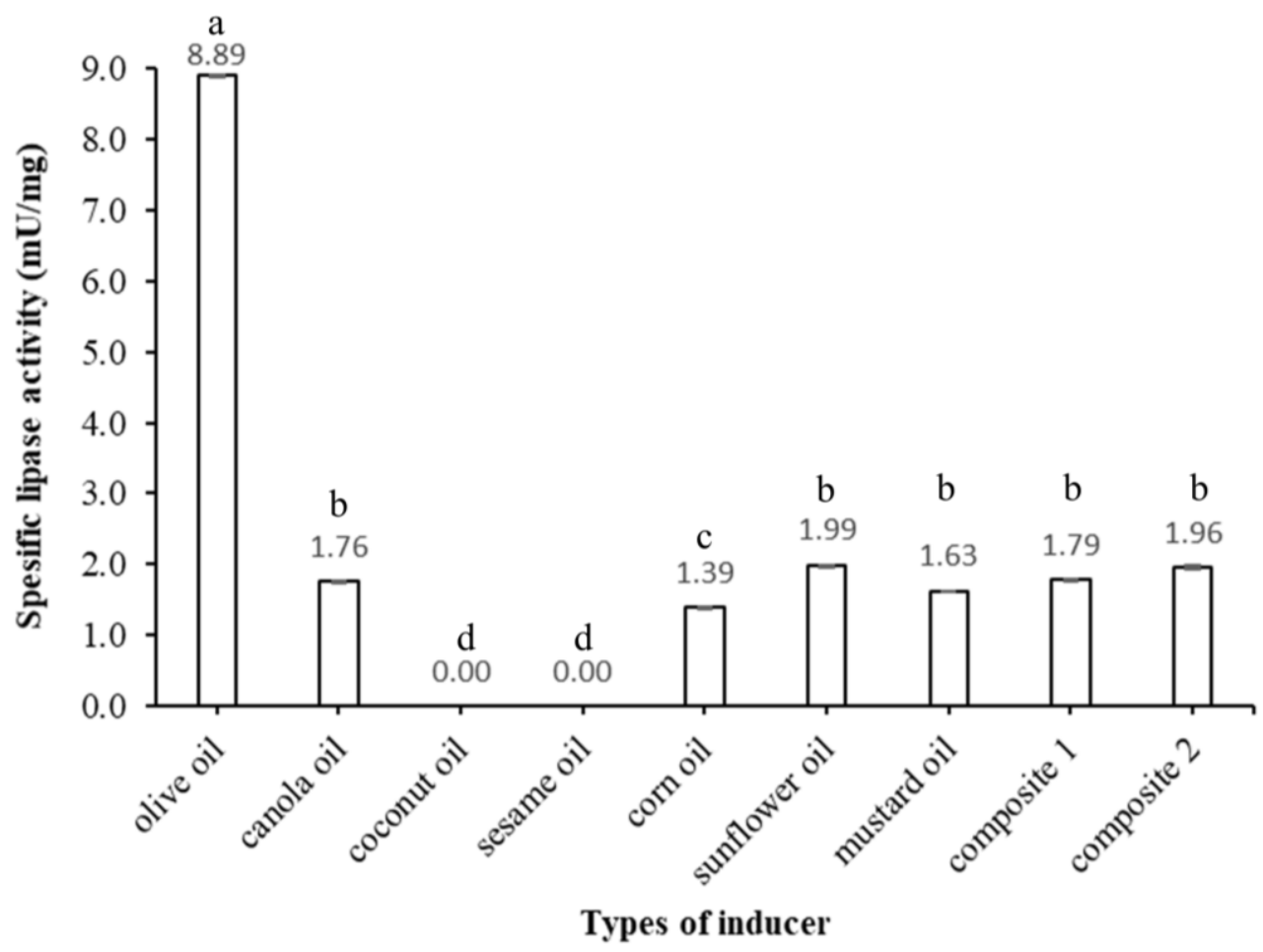

Fig. 2. Effect of types of inducers on the production of lipase by Rhodococcus strain UCC 0009. No seed culture was added to the control system. The value of specific lipase activity was determined as averages of triplicate samples \pm standard errors. Statistically significant differences $(p<0.05)$ were observed among the tested group. Different letters were used to rank the most optimum factors to the least optimum $\left(\right.$ most optimum $={ }^{\text {a }}$; least optimum $={ }^{\mathrm{d}}$ ). 


\subsection{Effect of various metal ions}

Most of the time, the cultivation of biomass requires the presence of metal ions as essential minor nutrients in the medium [18]. The metal ions can also perform as co-factor for several biosynthetic enzymes [18]. In the present investigation, the effect of several metal ions on lipase production by Rhodococcus strain UCC 0009 was determined by integrating the sources individually in the medium. The specific lipase activity was slightly enhanced (around $31 \%$ ) in the presence of $\mathrm{K}^{+}, \mathrm{Mg}^{2+}$, and $\mathrm{Ca}^{2+}$, whereas $\mathrm{Ba}^{2+}$ and $\mathrm{Co}^{2+}$ hampered lipase production by $72 \%$ compared to the control system (Table 2). These findings are similar to the study carried out by El-Ghonemy et al. [18]. However, some studies reported that lipase activity was severely inhibited in the presence of metal ions, which may be due to distorted conformation that impacts the enzyme [25].

Table 2. Effect of various metal ions on the production of lipase from Rhodococcus strain UCC 0009.

\begin{tabular}{|c|c|c|}
\hline No. & Metal ions & Specific lipase activity $(\mathrm{mU} / \mathrm{mg})$ \\
\hline 1. & $\mathrm{~K}^{+}$ & $11.19^{\mathrm{a}} \pm 0.00$ \\
\hline 2. & $\mathrm{Mg}^{2+}$ & $11.32^{\mathrm{a}} \pm 0.00$ \\
\hline 3. & $\mathrm{Ca}^{2+}$ & $11.67^{\mathrm{a}} \pm 0.00$ \\
\hline 4. & $\mathrm{Ba}^{2+}$ & $2.53^{\mathrm{c}} \pm 0.01$ \\
\hline 5. & $\mathrm{Co}^{2+}$ & $2.81^{\mathrm{c}} \pm 0.07$ \\
\hline 6. & $\mathrm{Control}$ & $8.90^{\mathrm{b}} \pm 0.05$ \\
\hline
\end{tabular}

No metal ions were added to the control system. The value of specific lipase activity was determined as averages of triplicate samples \pm standard errors. Statistically significant differences $(p<0.05)$ were observed among the tested group. Different letters were used to rank the most optimum factors to least optimum $\left(\right.$ most optimum $=$ a ; least optimum $={ }^{\mathrm{d}}$ ).

\section{Conclusion}

A novel isolate, Rhodococcus strain UCC 009, with high specific lipase activity, was discovered for potential application in converting waste cooking oil into biodiesel and glycerol, for instance in this study. The optimized conditions subsequently improved lipase production by $162 \%(4.45 \pm 0.01 \mathrm{mU} / \mathrm{mg}$ to $11.67 \pm 0.00 \mathrm{mU} / \mathrm{mg})$. The optimized growth conditions developed in this study can be used for mass production for industrial purposes. Further study using response surface methodology (RSM) should be carried out to elucidate the interaction between factor for enhanced lipase production by this locally isolated bacterium.

\section{Acknowledgements}

The authors would like to acknowledge the Selangor State Government and Universiti Selangor (Unisel), Malaysia for providing the Geran Penyelidikan Negeri Selangor (GPNS-01/Unisel/18-002) to support this research work. 


\section{References}

1. S. Javed, F. Azeem, S. Hussain, I. Rasul, M.H. Siddique, M. Riaz, H. Nadeem, Bacterial lipases: A review on purification and characterization, Prog. Biophys. Mol. Biol. 132, 23-34 (2018) https://doi.org/10.1016/j.pbiomolbio.2017.07.014

2. D.A. Sánchez, G. M. Tonetto, M.L. Ferreira, Burkholderia cepacia lipase: A versatile catalyst in synthesis reactions, Biotechnol. Bioeng. 115(1), 6-24 (2018) https://doi.org/10.1002/bit.26458

3. N. Sarmah, D. Revathi, G. Sheelu, K. Yamuna Rani, S. Sridhar, V. Mehtab, C. Sumana, Recent advances on sources and industrial applications of lipases, Biotechnol. Prog. 34(1), 5-28 (2018) https://doi.org/10.1002/btpr.2581

4. S. Shamim, U. Liaqat, A. Rehman, Microbial lipases and their applications - A review, Abasyn Journal of Life Sciences (AJLS) 2(1), (2018)

5. P. Chandra, R. Singh, P.K. Arora, Microbial lipases and their industrial applications: A comprehensive review, Microb. Cell Fact. 19(1), 1-42 (2020) https://doi.org/10.1186/s12934-020-01428-8

6. M. Suci, R. Arbianti, H. Hermansyah, Lipase production from Bacillus subtilis with submerged fermentation using waste cooking oil, in IOP Conference Series: Earth and Environmental Science (Vol. 105, No. 1, p. 012126). IOP Publishing Ltd. (2018, January) https://doi.org/10.1088/1755-1315/105/1/012126

7. N.M. Maegala, S. Anupriya, A.H. Hazwan, Y.N. Suhaila, A. Hasdianty, Conversion of waste cooking oil to glycerol by halal microbial lipase, in IOP Conference Series:

Earth and Environmental Science (Vol. 505, No. 1, p. 012056). IOP Publishing. (2020, July) https://doi.org/10.1088/1755-1315/505/1/012056

8. D. Tischler, W.J. Van Berkel, M.W. Fraaije, Actinobacteria, a source of biocatalytic tools, Front. Microbiol. 10, 800 (2019) https://doi.org/10.3389/fmicb.2019.00800

9. D. Kim, K.Y. Choi, M. Yoo, G.J. Zylstra, E. Kim, Biotechnological potential of Rhodococcus biodegradative pathways, J. Microbiol. Biotechnol. 28(7), 1037-1051 (2018) https://doi.org/10.4014/jmb.1712.12017

10. M.S. Kuyukina, I.B. Ivshina, Bioremediation of contaminated environments using Rhodococcus, in Biology of Rhodococcus (pp. 231-270). Springer, Cham. (2019)

11. M.N. Maniyam, N.S. Yaacob, H.H. Azman, N.A. Ab Ghaffar, H. Abdullah, Immobilized cells of Rhodococcus strain UCC 0004 as source of green biocatalyst for decolourization and biodegradation of methyl orange, Biocatal. Agric. Biotechnol. 16, 569-578 (2018) https://doi.org/10.1016/j.bcab.2018.10.008

12. M.N. Maniyam, A.L. Ibrahim, A.E. Cass, Decolourization and biodegradation of azo dye methyl red by Rhodococcus strain UCC 0016, Environ. Technol. 41(1), 71-85 (2020) https://doi.org/10.1080/09593330.2018.1491634

13. M.N. Maniyam, M. Hari, N.S. Yaacob, Enhanced methylene blue decolourization by Rhodococcus strain UCC 0003 grown in banana peel agricultural waste through response surface methodology, Biocatal. Agric. Biotechnol. 23, 101486 (2020) https://doi.org/10.1016/j.bcab.2019.101486

14. Y.N. Suhaila, A. Hasdianty, N.M. Maegala, A. Aqlima, A.H. Hazwan, M. Rosfarizan, A.B. Ariff, Biotransformation using resting cells of Rhodococcus UKMP-5M for phenol degradation, Biocatal. Agric. Biotechnol. 21, 101309 (2019) https://doi.org/10.1016/j.bcab.2019.101309

15. M.N. Maniyam, F. Sjahrir, A. Latif Ibrahim, A.E. Cass, Enzymatic cyanide degradation by cell-free extract of Rhodococcus UKMP- 5M, J. Environ. Sci. Health. Part A. 50(4), 357-364 (2015) http://dx.doi.org/10.1080/10934529.2015.987524 
16. F. Sjahrir, M.N. Maniyam, A. Latif Ibrahim, A.E. Cass, Biotransformation of acrylonitrile using immobilized cells of Rhodococcus UKMP-5M as biocatalyst, Indian J. Fundam. Appl. Life Sci. 6(1), 58-67 (2016) http://dx.doi.org/10.4314/jfas.v10i6s.41

17. A. Mehta, U. Bodh, R. Gupta, Isolation of a novel lipase producing fungal isolate Aspergillus fumigatus and production optimization of enzyme, Biocatal. Biotransfor. 36(6), 450-457 (2018) https://doi.org/10.1080/10242422.2018.1447565

18. S.E. Helal, H.M. Abdelhady, K.A. Abou-Taleb, M.G. Hassan, M.M. Amer, Evaluation of factors affecting the fungal lipase production using one factor at a time approach and response surface methodology, Egypt. J. Microbiol. 52(1), 1-16 (2017) https://doi.org/10.21608/ejm.2017.602.1012

19. F.A. Riyadi, M.Z. Alam, M.N. Salleh, M. N., H.M. Salleh, Optimization of thermostable organic solvent-tolerant lipase production by thermotolerant Rhizopus sp. using solid-state fermentation of palm kernel cake, 3 Biotech. 7(5), 300 (2017) https://doi.org/10.1007/s13205-017-0932-1

20. D.H. El-Ghonemy, M.S. El-Gamal, A. E. Tantawy, T.H. Ali, Extracellular alkaline lipase from a novel fungus Curvularia sp. DHE 5: Optimisation of physicochemical parameters, partial purification and characterisation, Food Technol. Biotechnol. 55(2), 206-217 (2017) https://doi.org/10.17113/ftb.55.02.17.4958

21. B.K. Sethi, P.K. Nanda, S. Sahoo, Characterization of biotechnologically relevant extracellular lipase produced by Aspergillus terreus NCFT 4269.10, Braz. J. Microbiol. 47(1), 143-149 (2016) http://dx.doi.org/10.1016/j.bjm.2015.11.026

22. A.I. El-Batal, A.A Farrag, M.A. Elsayed, A.M. El-Khawaga, Effect of environmental and nutritional parameters on the extracellular lipase production by Aspergillus niger, Int. Lett. Nat. Sci. 60, 11 (2016) https://doi.org/10.18052/www.scipress.com/ILNS.60.18

23. D.N. Putri, A. Khootama, M.S. Perdani, T.S. Utami, H. Hermansyah, Optimization of Aspergillus niger lipase production by solid state fermentation of agro-industrial waste, Energy Rep. 6, 331-335 (2020) https://doi.org/10.1016/j.egyr.2019.08.064

24. A. Das, S. Bhattacharya, S. Shivakumar, S. Shakya, S. S.S Sogane, Coconut oil induced production of a surfactant-compatible lipase from Aspergillus tamarii under submerged fermentation, J. Basic Microbiol. 57(2), 114-120 (2017) https://doi.org/10.1002/jobm.201600478

25. W.M. de Azevedo, L.F.R de Oliveira, M.A. Alcântara, A.M.T.D.M. Cordeiro, K.S.F.D.S.C. Damasceno, C.F.D. Assis, F.C.D. Sousa Junior, Turning cacay butter and wheat bran into substrate for lipase production by Aspergillus terreus NRRL255, Prep. Biochem. Biotech. 1-8 (2020) https://doi.org/10.1080/10826068.2020.1728698 